\title{
EDITORIAL
}

\section{Teaching and Training in Medical Education : Need for an Update}

Health care delivery is a concerted and systematic process. Multiple factors influence the effectiveness and outcome. Personnel like physicians, nurses, paramedics; resources and facilities available and efficient management are the major determinants. No doubt skill and competence of the working physician remains at the centre of all activities pertaining to health care delivery to the people. Teaching and training of graduate and post-graduate students should therefore intend to defining and achieving required competencies of a physician to deliver patient care in a suitable setting.

About 100 years back Flexner proposed reorientation and reorganization of medical education after a survey of 155 existing medical schools in USA and Canada amid widespread concern about performance and competency ( Flexner A 1910$)^{1}$. It established the basis for the adoption of scientifically designed curriculum and the standards for medical education that continue to the present day. Flexner recommended for a) high admissions standards, b) a university-based medical school to train students to think like scientists c) supervised clinical experience in a teaching hospital and d) Instructions by physician-scientists . He also strongly recommended that medical schools should employ fulltime clinical professors, who would become "true university teachers barred from all but charity practice, in the interest of teaching."

Remarkable reforms for an effective educational program for preparation of physicians were planned along with reorganization of healthcare system. These efforts integrated medical education, research and health care. Medical curricula were updated within the framework of universities. Partnership between clinicians and academics came together to develop new methods of improving medical education and increasing patient safety. Development of professionalism including humanistic qualities such as caring, empathy, modesty, compassion, social responsibility, and sensitivity to people's culture and belief, which lie at the heart of a patient centered approach was given more emphasis in designing curricula for graduate and postgraduate courses. ${ }^{2}$

The effect of reforms in USA had a global impact. Similar efforts were made in the UK, European countries and in other parts of the globe. Regional centers were developed to help re-orientation process in different countries. Last century thus became a century of reforms. At the beginning there was a science based curriculum. By mid century there was a call for problem based approach to cope up with increasing complexity of psycho-social and financial problems. By the end of the century there is a call for a system based approach to medical education and training. Different countries and institutions has adopted these changes in parts giving rise to a mixed pattern in medical curricula. ${ }^{2,3}$

Target of these reforms could not be attained .There were problem areas like knowledge poorly linked to experience; inappropriate assessments; and missed opportunities for allowing learners to participate in the important nonclinical roles physicians play within health care and more broadly in society. There is mismatch between competencies to patient care and population needs, poor teamwork, episodic encounters in place of continuous care and too much reliance on hospital care in place of primary care .

Moreover there are fresh challenges to address in the new millennium. New infection and rapidly rising noncommunicable disease, environmental and behavioral risk, ageing population, fast demographic and epidemiological shifts are among them. New scientific inventions specially in molecular biology and information technology and heightened expectation are compelling forces to consider updating of medical curricula and training so that new graduates and specialist are ready to take challenge and also to be capable to learn by themselves what is required for them to achieve their goal of competent care. 
This millennium began with new target " Millennium Development Goal ( MDG )" that match with other frontiers of scientific and socio-political development. Professional leaders and Academics have joined together to lay down the future of medical workforce and health care delivery. General medical council of UK has formulated "Tomorrow's Doctor", a document that will guide shaping of future graduates. ${ }^{4}$ Similar other documents from different countries also echoed alike. ${ }^{5-9}$. A global independent commission examined the issue of medical education and advised instructional and institutional changes to ensure and improve system performance. Instructional reforms should include a shift to competency based approach with a capability to adapt competencies to local needs. Commission also suggested for intra-professional and trans-professional education. They also recommended utilization of IT for learning and development of educational resources.

A social movement for revitalization of medical education and training is the demand of the time. New professionalism that is patient centered and team-based remains the aspiration of concerned professionals. Australian Medical Association has proposed a competency based curricula and training for graduate doctors and post-graduate specialists. ${ }^{10}$ Assessment system to evaluate the achievement of expected competencies has also been integral part of the regulation drawn up by the professional body. The introduction of competency-based training in graduate and post graduate medical education has been a proactive response to increase the transparency, accountability and efficiency of training programs in the face of a changing healthcare environment. These competency frameworks are expected to add value to medical education and training by promoting higher order skills required of doctors, providing guidance for curriculum development, providing guidance to learners and teachers, and to identify the required infrastructure and support to deliver training. A number of other documents from other countries have also been published. Institute for International medical education has devloped a document stating the minimum required standard of medical colleges. ${ }^{10}$ The WFME has published WFME Global Standards for Quality Improvement and WHO/WFME Guidelines for Accreditation of Basic Medical Education. ${ }^{11}$ These documents are valuable guide for planning and adoption of our goals and strategy.
In our perspective, the challenge is far more complex. A large population, pitiable level of literacy, financial incapability and social complexity each has its own impact. Our curricula does not fall back to a great extent but implementation, specially assessment both formative and summative suffers because of mal distribution of teachers and resources. There is also discrepancy between trainee, trainers and training posts rendering post-graduate training grossly inefficient. We now need a reform that will address national needs and carefully set priorities in teaching and training of doctors who will be caring for our population. Other elements of patient care and health delivery system like nursing personals and technologists, resource allocation and logistic support has to be considered to work as efficient team and have a holistic impact.

There is an urgent need for formulating a competency based training program divided according to complexity of contents and arranged as modules so that trainees have exposure and experience in each of the area required for intended specialty. Present system of honorary training must stop These trainees must be paid so that they will devote completely into their training. For implementation a higher education training council shall have to be formed where the Government, trainers, Medical council and funding agencies come to a platform and monitor training and teaching and also evaluation process at accredited institutions. A transparent quality assurance and accountability is also required to accomplish the much cherished goal of a competent doctor.

(J Bangladesh Coll Phys Surg 2011; 29: 183-185)

\section{Md Margub Hussain}

Professor of Surgery

Dhaka Medical College and

Dean,

Faculty of post-graduate Medical Science and Research Dhaka University.

\section{References:}

1. Flexner A.(1910), Medical Education in the United States and Canada: A Report to the Carnegie Foundation for the Advancement of Teaching, Bulletin No. 4., New York City: The Carnegie Foundation for the Advancement of Teaching, pp. 346 
2. Cooke M, Irby D, and O'Brien B, Educating Physicians: A Call for Reform of Medical School and Residency (Flexner report II ) Jossey-Bass, San Francisco 2010.

3. Frenk J, Chen L, Bhutta Z A et al (2010) Health professionals for a new century: transforming education to strengthen health systems in an interdependent world The Lancet, Volume 376, Issue 9756, Pages 1923 - 1958

4. UK General Medical Council. Tomorrow's doctors: outcomes and standards for undergraduate medical education. London: General Medical Council, 2009.

5. Josiah Macy Jr Foundation. Revisiting the medical school educational mission at a time of expansion. Charleston: Josiah Macy Jr Foundation, 2008.

6. Benner P, Sutphen M, Leonard V, Day L. Educating nurses: a call for radical transformation. Stanford: The Carnegie Foundation for the Advancement of Teaching, 2010.
7. Cooke M, Irby DM, O’Brien BC, Shulman LS. Educating physicians: a call for reform of medical school and residency. Stanford: The Carnegie Foundation for the Advancement of Teaching, 2010 .

8. The Association of Faculties of Medicine of Canada. The future of medical education in Canada (FMEC): a collective vision for MD education. Ottawa: The Association of Faculties of Medicine of Canada, 2010.

9. Association of American Medical Colleges. A snapshot of medical student education in the United States and Canada. Acad Med 2010; 85: S1-S648.

10. Institute of International Medical Education ( IIME) "Global Minimum Essential Requirements"

11. WFME Global Standards for Quality Improvement and WHO/ WFME Guidelines for Accreditation of Basic Medical Education. WFME ( World Federation of Medical Education) 2010. 